\title{
Neumotórax bilateral espontáneo como forma de presentación de histiocitosis de células de Langerhans
}

\author{
Bilateral spontaneous pneumothorax as a setting of Langerhans cell \\ histiocytosis
}

Dr. Jesús Javier Martínez García ${ }^{a}$ Dra. Mirna Guadalupe Rios Osuna $a^{b}$ Dr. Eduardo Altamirano Álvarez ${ }^{b}$

\begin{abstract}
RESUMEN
La histiocitosis de células de Langerhans pulmonar es una patología intersticial en la que existe un acúmulo de células histiocíticas específicas a nivel pulmonar. El neumotórax espontáneo es una complicación reconocida de histiocitosis de células de Langerhans pulmonar y es secundario a la destrucción del parénquima pulmonar con cambios quísticos asociados. Reportamos el caso de un niño de 2 años con neumotórax espontáneo bilateral recurrente, con una tomografía axial computada de tórax con infiltrado intersticial, fibrosis, lesiones quísticas e imágenes bullosas. El diagnóstico fue establecido por examen histológico e inmunohistoquímica de tejido de biopsia pulmonar con anticuerpos CD1 yS100 positivos. El niño recibió tratamiento con prednisona y etopósido, con buena respuesta clínica y tomográfica.

Palabras clave: neumotórax espontáneo, histiocitosis de células de Langerhans pulmonar.
\end{abstract}

\begin{abstract}
Pulmonary Langerhans cell histiocytosis is an interstitial lung disease that results from the accumulation of specific histiocytic cells in the lung. Spontaneous pneumothorax is a recognized feature of pulmonary Langerhans cell histiocytosis and results from destruction of lung parenchyma with associated cystic changes.

We report on a 2-year-old boy with recurrent bilateral spontaneous pneumothorax; a computed tomography scan showed marked interstitial changes, fibrosis, cystic spaces and bilateral bullae. The diagnosis was confirmed by the histology and the immunohistochemistry examination of the pulmonary biopsy with CD1 and S100 positive antibodies.

The child was treated with prednisone and etoposide, and had a good clinical response and favorable changes in the second thoracic CT scan.

Key words: spontaneous pneumothorax, pulmonary Langerhans cell histiocytosis.
\end{abstract}

http:/ /dx.doi.org/10.5546/aap.2014.e113

a. Unidad de Terapia Intensiva Pediátrica.

b. Servicio de Hematología y Oncología.

Hospital Pediátrico de Sinaloa, Dr. Rigoberto Aguilar Pico. México.

Correspondencia:

Dr. Jesús Javier Martínez García, jjmtz64@hotmail.com

Conflicto de intereses: ninguno que declarar.

Recibido: 1-11-2013.

Aceptado: 2-1-2014.

\section{INTRODUCCIÓN}

La histiocitosis de células de Langerhans (HCL) comprende un grupo de enfermedades con diferente curso clínico. Previamente, se incluían en este grupo el granuloma eosinofílico, la enfermedad de Hand-Schüller-Christian y la enfermedad de Letterer-Siwe. Luego, se agruparon como histiocitosis X, que, en 1987, fue clasificada como histiocitosis de células de Langerhans. ${ }^{1-2}$

La HCL tiene una presentación variable: puede afectar a un solo órgano, como hueso, piel, nódulos linfáticos, pulmón y glándula pituitaria, o ser de afectación multisistémica, que incluye el sistema hematopoyético, hígado, bazo y pulmones, y que tiene una mortalidad significativamente alta. ${ }^{3-4}$

La afectación pulmonar por HCL es muy rara en niños; contrariamente, en adultos, se reporta entre un 90 y un $100 \%$ de asociación entre HCL pulmonar y antecedentes de tabaquismo. ${ }^{5-6}$

Se desconoce la prevalencia de HCL pulmonar. Informes de una serie de biopsias pulmonares en pacientes adultos con patología pulmonar intersticial reportan una frecuencia del 5\% de HCL pulmonar. ${ }^{7}$ En una serie de 1382 pacientes adultos con patología pulmonar difusa, en 91 $(6,6 \%)$, se estableció el diagnóstico de HCL pulmonar. $^{8}$

Los pacientes con HCL pulmonar presentan síntomas respiratorios inespecíficos, como tos, disnea, fiebre, pérdida de peso y, en el $10-15 \%$, puede presentarse neumotórax espontáneo. ${ }^{9}$

En la radiografía de tórax, con frecuencia, se observan infiltrados micronodulares o infiltrados reticulares e imágenes quísticas con una distribución simétrica en ambos pulmones. La tomografía computada de pulmón es una herramienta esencial para establecer el diagnóstico de HCL pulmonar, y los principales hallazgos incluyen nódulos y quistes primariamente en lóbulos superiores, pero el diagnóstico definitivo requiere la demostración histológica de lesiones típicas, que contienen 
células de Langerhans en el tejido pulmonar, la presencia de gránulos de Birbeck por microscopia electrónica y de anticuerpos CD1a y S100 por inmunohistoquímica. ${ }^{10-12}$

\section{Descripción del caso}

Niño de 2 años de edad, previamente sano, que presenta, con una semana de evolución, fiebre, hiporexia, rinorrea, tos y dificultad respiratoria progresiva.

Padre con tabaquismo positivo como único antecedente relevante para la patología al momento de su internación. Ingresa al Servicio de Terapia Intensiva Pediátrica por dificultad respiratoria grave, taquicardia e hipoxemia. $\mathrm{La}$ radiografía de tórax inicial muestra neumotórax bilateral a tensión (Figura 1) y la tomografía axial computada de tórax, áreas bilaterales septadas de aspecto bulloso e incremento difuso en la densidad pulmonar, infiltrado intersticial, áreas de fibrosis con lesiones quísticas y neumotórax bilateral (Figura 2).

Requirió ventilación mecánica por 17 días, con mala evolución inicial por neumotórax bilateral recurrente tratado con drenaje pleural. Se realizó biopsia pulmonar basal izquierda, y la descripción microscópica realizada reportó obliteración de la histología normal del pulmón por infiltración en parches o focos de células de citoplasma abundante, eosinófilos y núcleos redondos ovales y de forma reniforme. Se observaron núcleos con hendidura longitudinal, otros con nucleolo prominente, macrófagos espumosos, células gigantes multinucleadas y abundantes eosinófilos, fibrosis, hemorragia y cúmulos de linfocitos entre la proliferación de células dendríticas. Por inmunohistoquímica, se informan anticuerpos CD1a y S100 positivos (Figura 3).

Se establece el diagnóstico de histiocitosis de células de Langerhans pulmonar. Se descartó la afectación de otros órganos. El tratamiento se efectuó sobre la base de 3 ciclos de quimioterapia con etopósido (VP 16) a $100 \mathrm{mg} / \mathrm{m}^{2} /$ día y prednisona a $40 \mathrm{mg} / \mathrm{m}^{2} /$ día para el primer ciclo y VP 16 a $100 \mathrm{mg} / \mathrm{m}^{2} /$ día, vinblastina a $2,5 \mathrm{mg} /$ $\mathrm{m}^{2} /$ día y prednisona a $40 \mathrm{mg} / \mathrm{m}^{2} /$ día para el $2^{\text {do }}$ y el $3^{\text {er }}$ ciclo, respectivamente.

La evolución fue satisfactoria; la tomografía computada de tórax de control a los 8 meses mostró lesiones quísticas ovoides con paredes delgadas, con resolución de las lesiones mostradas en la primera tomografía y sin recurrencia de neumotórax hasta la actualidad (Figura 4).

\section{DISCUSIÓN}

Se desconoce la etiología del neumotórax espontáneo primario; la hipótesis de este problema son los cambios en el tejido conectivo pulmonar que se desarrollan lentamente hasta formar bullas, que son detectadas por tomografía axial computada en el $28-100 \%$ de los casos. En el neumotórax espontáneo secundario, las principales causas se dividen en patologías primarias o infecciosas de pulmón: asma, fibrosis quística, enfisema intersticial, tuberculosis, neumonía necrotizante y absceso pulmonar. Procesos inflamatorios y enfermedades del tejido conectivo: histiocitosis de células de Langerhans,

FIgURA 1. Radiografía de tórax. Neumotórax bilateral a tensión

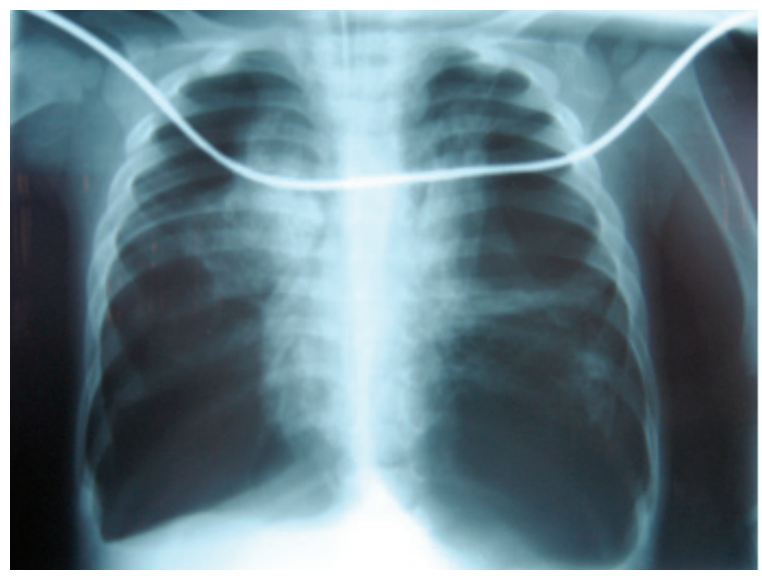

FIgURA 2. Tomografía computada de tórax. Imágenes de aspecto bulloso, infiltrado intersticial, áreas de fibrosis con lesiones quísticas difusas basales y neumotórax bilateral

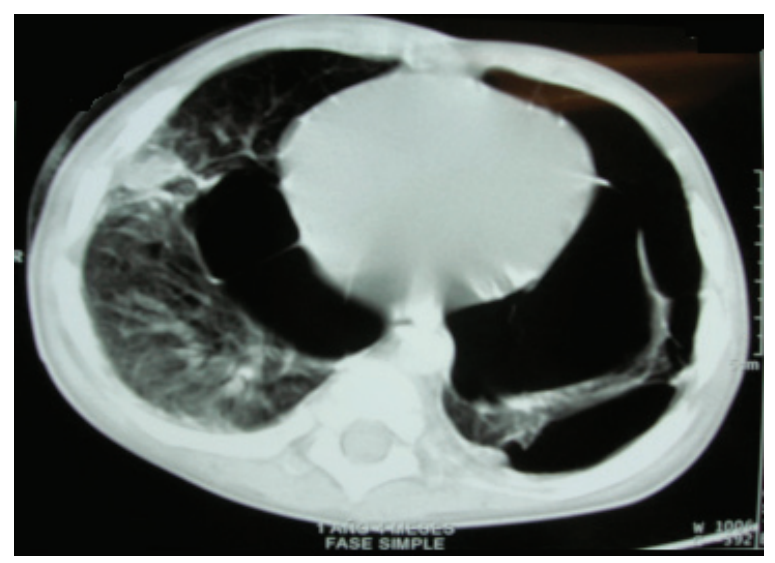


Figura 3. A, B: Infiltrado por eosinófilos y células de Langerhans en biopsia de tejido pulmonar, por microscopia electrónica. C, D: Células de Langerhans en la tinción inmunohistoquímica positivas para el antígeno CD1 y S100

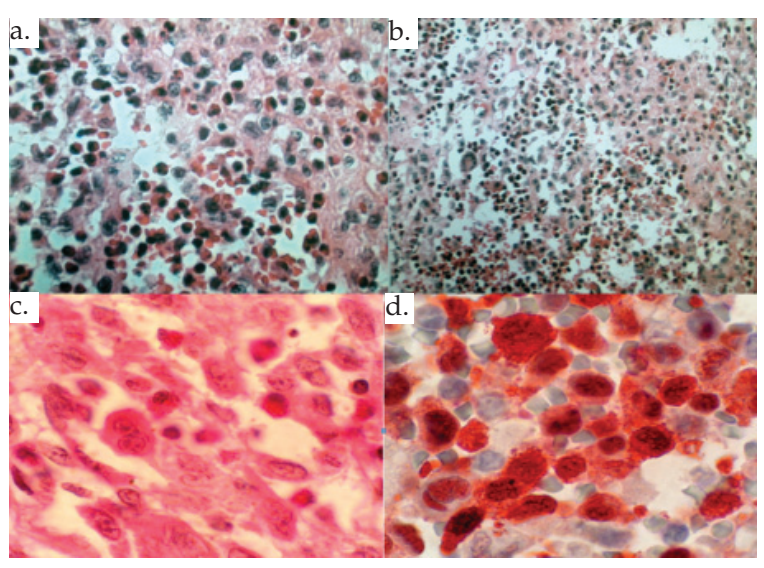

FIgURA 4. Tomografía axial computada pulmonar 8 meses después de tratamiento; muestra lesiones bilaterales quísticas ovoides con paredes delgadas y áreas de fibrosis

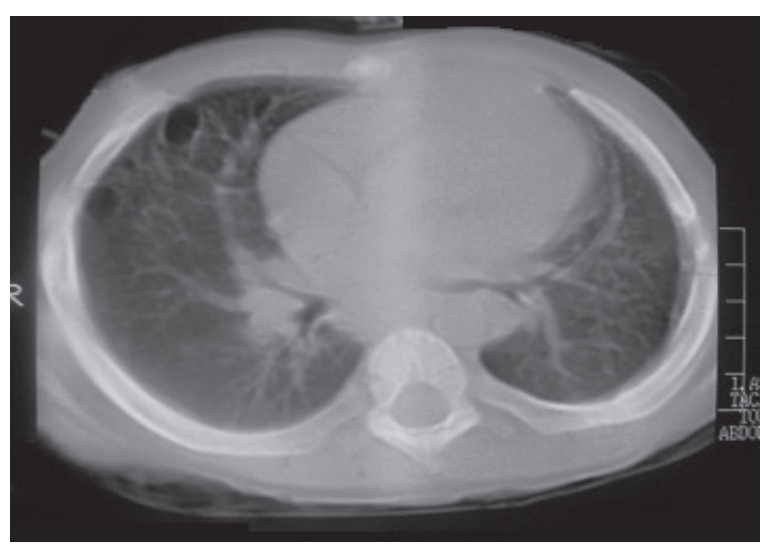

linfomas, metástasis, deficiencia de $\alpha_{1}$ antitripsina, síndrome de Marfan, síndrome de Ehlers-Danlos y artritis idiopática juvenil, entre otras. ${ }^{12}$

El compromiso pulmonar en la $\mathrm{HCL}$ multisistémica es aproximadamente del 20 al $40 \%$ de los casos, y la afectación pulmonar observada en niños es parte de esta enfermedad generalizada. En contraste, la HCL pulmonar se observa principalmente en adultos jóvenes y no en niños, sobre todo por su estrecha relación con el tabaquismo, que condiciona una enfermedad intersticial pulmonar caracterizada por bullas, quistes o nódulos con o sin cavitación, que se presentan en la vía aérea de pequeño calibre, con tracción de áreas de enfisema y distensión pulmonar, que aumentan el riesgo de neumotórax. ${ }^{10,13}$

En una muestra de 102 pacientes con HCL pulmonar confirmado histológicamente, el $16 \%(n=16)$ presentó uno o más episodios de neumotórax. De estos, en 11 pacientes (69\%), la manifestación inicial fueron neumotórax espontáneos, con recurrencia del 4 al 17\% y mortalidad del 16\%, relacionada con neumotórax recurrente. ${ }^{14}$ En este mismo estudio de casos y controles, se observó que los pacientes con HCL pulmonar tratados solo con observación o sonda pleural presentaron una recurrencia del neumotórax del $58 \%$ en un tiempo de $127 \pm 81$ meses de seguimiento, mientras que aquellos pacientes bajo tratamiento quirúrgico (pleurodesis mecánica, pleurectomía o pleurodesis química) no tuvieron recurrencia de neumotórax. ${ }^{14}$

El pronóstico de pacientes con HCL pulmonar que recibieron quimioterapia fue favorable en más del 50\% de los casos, con recuperación de las lesiones pulmonares y de las pruebas de función pulmonar. En estos pacientes, es muy importante realizar un seguimiento con reevaluaciones cada 6 meses, con controles de tomografía axial computada de pulmón y pruebas de función pulmonar. La reactivación de la enfermedad es una complicación poco frecuente de la HCL pulmonar y el seguimiento a largo plazo es muy importante, sobre todo porque la función pulmonar se puede ver afectada por la fibrosis pulmonar, que disminuye la capacidad vital. ${ }^{15,16}$

\section{Agradecimientos}

Al personal del laboratorio de Patología del Hospital Infantil de México “Dr. Federico Gómez" por el apoyo en los estudios de inmunohistoquímica.

\section{BIBLIOGRAFÍA}

1. Alavi S, Ashena Z, Paydar A, Hemmati N. Langerhans cell histiocytosis manifesting as recurrent simultaneous bilateral spontaneous pneumothorax in early infancy. Pediatr Int 2007;49(6):1020-2.

2. Al-Trabolsi HA, Alshehri M, Al-Shomrani A, Shabanah M, Al-Barki AA. "Primary" Pulmonary Langerhans Cell Histiocytosis in a Two-Year-Old Child: Case report and literature review. J Pediatr Hematol Oncol 2006;28(2):79-81.

3. Márquez-Vega C, Delgado-Pecellín I, Ramírez-Villar G. Tension pneumothorax as unusual cause of isolated pulmonary histiocytosis in paediatrics. Arch Bronconeumol 2011;47(4):215-6. 
4. Vassallo R, Ryu JH, Schroeder DR, Decker PA, Limper AH. Clinical outcomes of pulmonary Langerhans' cell histiocytosis in adults. N Engel J Med 2002;346(7):484-90.

5. Schulze J, Kitz R, Grüttner H, Schmidt H, Zielen S. Severe isolated Langerhans cell histiocytosis in a 6-year-old girl. Eur J Pediatr 2004;163:320-2.

6. Vassallo R, Ryu JH. Pulmonary Langerhans' cell histiocytosis. Clin Chest Med 2004;25:561-71.

7. Matsubayashi T, Miwa Y, Saito I, Matsubayashi R. KL-6: Marker for Pulmonary Involvement in Langerhans Cell Histiocytosis in Infants. J Pediatr Hematol Oncol 2004;26:584-6.

8. Bubala H, Sonta-Jakimczyk D, Gregor J, Dzielicki J. Recurrent pneumothorax in a child with Langerhans cell Histiocytosis. Pneumonol Alergol Pol 2001;69:93-6.

9. Oklen A, Mocan H, Erduran E, Aslan Y, et al. Langerhans cell Histiocytosis associated with recurrent Pneumothorax: a case report. Turk J Pediatr 1996;38:125-30.

10. Alter SJ. Spontaneous pneumothorax in infants: 10-year review. Pediatr Emerg Care 1997;13(6):401-3.
11. Eren S, Gurkan F, Balci A, Ulku R, et al. Spontaneous pneumothorax in children in the South-east of Turkey. Pediatr International 2004;46:580-2.

12. Dotson K, Johnson LH. Pediatric Spontaneous Pneumothorax. Pediatr Emerg Care 2012;28:715-23.

13. VarkkiS, Tergestina M, Bhonsle VS, Moses PD, et al. Isolated Pulmonary Langerhans Cell Histiocytosis. Indian J Pediatr 2013;80:700-3.

14. Braier J, Latella A, Balancini B, Castaños C, Goldberg J. Isolated Pulmonary Langerhans Cell Histiocytosis Presenting With Recurrent Pneumothorax. Pediatr Blood Cancer 2007;8:241-4.

15. Mendez JL, Nadrous HF, Vassallo R, Decker PA, Ryu JH. Pneumothorax in Pulmonary Langerhans Cell Histiocytosis. Chest 2004;125:1028-32.

16. Nagy B, Soós G, Nagy K, Dezso B. Natural Course of Isolated Pulmonary Langerhans' Cell Histiocytosis in a toddler. Respiration 2008;75:215-20. 